\title{
Derechos de patronato y movimientos populares en el sur de Córdoba durante los siglos XVI al XVIII
}

\author{
REMEdios MORÁN MARTIN*
}

En el Archivo Señorial de Benamejí (ASB), principalmente en el legajo $18, n .{ }^{\circ} 1$ al 14 , se conserva parte del pleito seguido por el señor de Benameji y el prior de San Marcos de León sobre la jurisdicción eclesiástica de la villa de Benamejí, iniciado a finales del siglo XVI y que se alarga hasta inicios del siglo XIX.

A pesar de lo puntual del tema, su estudio nos pareció interesante por dos motivos: en primer lugar por el tema en sí, la lucha por la jurisdicción eclesiástica de una villa de pequeña significación económica y geográfica y las incidencias que dicho conflicto tuvo a lo largo de siglos. En segundo lugar porque, a diferencia de lo que ocurre en otros muchos lugares, el pueblo en pleno se afilió al partido del señor, apoyándolo con las medidas que tuvo a su alcance.

\section{Planteamiento del tema. antecedentes del Conflicto}

El término de Benamejí fue donado por Alfonso $X$ al maestre de la Orden de Santiago D. Pelay Pérez Correa, en el año 1254. Tras varias

* Departamento de Historia y Filosofía Juridicas (Historia del Derecho Español) UNED. 
incursiones musulmanas es conquistado definitivamente por Pedro I en 1362, fecha en la que vuelve a incorporarse a la Orden Militar ${ }^{1}$.

Dicha orden mantuvo la posesión del territorio hasta 1548, momento en el que Carlos I se ve obligado a desmembrar y enajenar tierras y jurisdicciones, entre ellas Benamejí y sus anejos. Los motivos que llevaron al emperador a tomar estas medidas fueron principalmente económicos: las precarias condiciones de la Hacienda en estos momentos y la consiguiente necesidad de aumentar los ingresos. El título jurídico que permitía dicha desmembración lo obtuvo en virtud de las Bulas y Breves apostólicos otorgados por Clemente VII y Paulo III en 1529 y 1538 respectivamente ${ }^{2}$.

La venta fue realizada por Maximiliano y doña María, fechada en Valladolid, el 24 de diciembre de 1548 y ratificada por Carlos I en Bruselas el 26 de marzo de 1549. El comprador será un burgués, Diego de Bernuy Orense, vecino y regidor de Burgos; hombre dedicado hasta entonces al comercio internacional de lana, metal y pastel y al préstamo de dinero, entre cuyos deudores figuró en varios momentos el mismo Carlos $\mathbf{I}^{3}$.

Tal como se relaciona en la carta de venta de Benamejí, se vende a Diego de Bernuy

«... para vos, y para quien vos quisieredes, y por bien tuviesedes, y de vos o dellos hobiere titulo, o causa para siempre jamas, el dicho heredamiento de Benameji, con sus terminos, y fortaleza, rentas, rios, montes, y jurisdiccion civil y criminal, alta, baja, mero mixto imperio con la propiedad y suelo del dicho heredamiento de Benameji, y de los otros heredamientos sus anejos, que son la dicha Dehesilla, Encina del Cuervo, y la Palenciana, y el dicho derecho de pacer en el dicho termino nombrado el Entredicho, y la propiedad, y jurisdicion del, si a la

D. W. LomaX: La Orden de Santiago: MCLXX-MCCLXXV, Madrid 1965, 113. M. A. Ladero Quesada: “La Orden de Santiago en Andalucia. Bienes, rentas y vasalios a fines del siglo XV", en Historia, Instituciones, Documentos, Sevilla, 2 1975, 340. M. GaRzón PA. REJA: Historia de Granada, I, Granada 1980, 99-100.

2 Vid. S. de Moxo: "Las desamortizaciones eclesiásticas en el siglo XVI", en A.H.D.E., Madrid, XXXI, 1961, 329 y ss. R. CARANDE: Carlos $V$ y sus banqueros, I, Madrid, 1977, 477. 479. M. Fernández Álvarez: Corpus documental de Carlos V. II, Salamanca 1975, 150, 369 y passim. Ibidem, III, Salamanca 1977, 21, 31, 43 y passim. R. MORAn Martin: El señorío de Benameji (su origen y su evolución en el siglo xvi), Córdoba 1986, 132-137.

3 Ibidem, 77-121. 
dicha orden pertenescia, con todos los diezmos y primicias de todo el dicho termino, y heredamientos, ansi de lo que este rompido, como de lo que de aqui adelante se rompiere, y meriere en labor, y lo que en ello se criare, y fructificare y plantare ansi prediales, como personales, como en otra cualquier manera que de derecho, o de costumbre se pueda deber, y con otras cualesquier preeminencias, que a la dicha orden y Mesa Maestral de ella, y a su Magestad como asministrador perpetuo de la dicha Orden pertenescian; y con el dicho derecho de cualquier parte de los dichos terminos y heredamiento que este usurpado, y tomado por los vecinos comarcanos de otras partes sin lo que de suso va exceptuado, y adelante ira declarado, con las dichas tierras, montes, pastos riveras, abrevaderos, moliendas hornos, caza, pesca y la dicha escribania y alguacilazgo y mesones y penas de Camara y de costas y tales $y$ el dicho derecho de presentar y poner clerigo o clerigos que sirvan en la Iglesia del dicho heredamiento, por la orden y manera y forma que el Maestre de la dicha orden hasta aqui lo ha hecho $y$ podido hacer, y otras cualesquier cosas de cualquier genero, cualidad, y natura que sea, que la dicha orden de Santiago y Mesa Maestral de ella y Su Magestad como administrador perpetuo de la dicha Orden había y tenía y le pertenescia e podia pertenescer en cualquier manera o por cualquier causa, titulo y razon..." ${ }^{4}$.

Nada más expresivo que los términos en que está redactada la carta de venta para la enumeración de los bienes y derechos adquiridos por el nuevo señor, a la vista de los cuales entramos en el tema que nos ocupa: el aspecto eclesiástico y los problemas que surgieron por el derecho de nombramiento y presentación de clérigos.

\section{RIVALIDAD ENTRE EL SEÑOR DE BENAMEJÍ Y EL PRIOR DE SAN MARCOS DE LEÓN SOBRE LA JURISDICCIÓN ECLESIÁSTICA DE BENAMEJÍ}

Tras la donación de Benamejí a la Orden de Santiago, fue incluida en el priorato de San Marcos de León, en la encomienda de Valencia del Ventoso y en la diócesis de Llerena.

Al estar aislada y lejos de su encomienda y diócesis los distintos comendadores la ignoran, tanto en el aspecto material como en el espi-

${ }^{4}$ A.S.B., Leg. 17, n. ${ }^{\circ} 8$, ff. $69 \mathrm{v}-70$. El subrayado es nuestro. 
ritual. Este tema se evidencia cuando en 1547, ante la inminencia de su desmembración y venta, fue enviado al término de Benamejí un visitador de la Orden, Juan de León, con el fin de evaluar todas las rentas del término. Su visita concluyó con el reconocimiento de que Benameji no estaba poblada más que por arrendadores temporales y que no habia en ella casas de ladrillo, sino chozas provisionales y que la zona estaba descuidada espiritualmente, sin iglesia adecuada y sin clérigo que la atendiera ${ }^{5}$.

Sin embargo, tenemos un dato importante en relación con el tema eclesiástico: En el Archivo de la Catedral de Córdoba se conserva una carta de Pelay Pérez, fechada el 16 de junio de 1260, en la que el maestre, con consentimiento del capítulo general de la Orden establece una concordia con Fernando de Mesa, obispo de Córdoba. En ella, la Orden se reserva el derecho de presentación de clérigos en Benameji y Bierben, salvo los privilegios y libertades de los obispos. Estos tendrán derecho a la percepción de ocho mrs. por la visita y corrección de seis iglesias de la Orden, a la décima de los diezmos y a la tercera parte de las penas por sacrilegio ${ }^{6}$.

Conciertos similares firmó la Orden en otros lugares, como por ejemplo el firmado por el mismo Pelay Pérez con el obispo de Sevilla?

A la vista de este documento nos surge una duda, ¿existió algún otro documento, además del privilegio de donación a Pelay Pérez, en el que el rey restringiera el poder del maestre en favor del obispo de Córdoba? Con los datos que poseemos lo único que podemos apreciar sobre el tema es que igual de inexpresiva es la carta de donación de Alfonso $X$ en el aspecto eclesiástico que clara la concordia, al hablar del derecho del maestre a la presentación de clérigos, salvando, por lo demás, los privilegios del obispo.

No obstante, el proceso de apropiación de facultades por parte de la Orden fue continuo y si bien en el caso de Benameji no llegó a ponerse en práctica en gran medida, se aprecia la intromisión en el nombramiento

${ }^{5}$ A.G.S., Expedientes de Hadcienda, Leg. 234. Vid., R. Morán Martín: El señorío de Benameji..., 48 y ss., $170-171$ y passim.

6 Archivo de la Catedral de Córdoba, C.O., n. ${ }^{\circ}$ 216. Apud. M. Nieto Cumplido: Corpus Mediaevale cordubense (1256-1277), II, Córdoba 1980, n. 589.

' M. A. Ladero Quesada: La orden de Santiago en Andalucia..., 335. 
de clérigos, en lugar del derecho de presentación, a juzgar por la transferencia del derecho al nuevo señor, Diego de Bernuy, tras la desamortización y venta del término por Carlos I.

El 1 de enero de 1549, Juan de Cisneros, en nombre de Diego de Bernuy, toma posesión de los distintos lugares del señorío, entre ellos la iglesia (que en este momento no era sino una especie de choza de palo y paja), con sus vestuarios, libros, cáliz, y otras cosas (que no llegaban a tener las condiciones mínimas para el culto) y nombró clérigo a Alonso Cañas-Vera, con lo que estamos ante el primer clérigo nombrado directamente por el señor ${ }^{8}$.

Meses después de la toma de posesión, en marzo de 1549, es otorgada la carta de población de Benamejí en los artículos 2 y 3 se estipula la edificación de la iglesia a costa del señor y el privilegio (mitad privilegio, mitad obligación) de poner en ella clérigos que la sirven y administren los sacramentos, estando obligados los señores a pagarles un salario como contrapartida del cobro de los diezmos y primicias, recogidos en los preceptos siguientes ${ }^{9}$.

Diego de Bernuy, al no poder edificar nueva iglesia restauró la pequeña ermita existente, pero dejó en su testamento una dotación de 5.000 .000 de mrs. (500.000 mrs. cada año durante una década) situados en las rentas de Benameji; si no fuese suficiente, pasados diez años, añade 1.000 fanegas de trigo durante otros seis años; y si aún faltasen recursos, manda que el resto sea pagado por sus herederos ${ }^{10}$.

Desde el nombramiento de Alfonso Cañas-Vera, anualmente el señor - en su nombre el alcalde mayor o el mayordomo nombraban curas beneficiados, capellanes y sacristanes, aumentando progresivamente el número de los mismos.

Según el testamento del primer señor, el salario que se les había de pagar era de 300 fanegas de trigo, 150 arrobas de vino y $15.000 \mathrm{mrs}$. en

${ }^{8}$ A.S.B., Leg. 17, n. ${ }^{\circ} 8$, fols. $81 v-82$.

${ }^{9}$ Archivo Municipal de Benameji, Carta puebla. s.c., s.f. También vid. J. de AzCArRaga Servet: "Carta puebla del señorio de Benameji”, en Revista de Historia del Derecho de la Universidad de Granada, Granada, II, 2, 1981, 319-343.

${ }^{10}$ A.S.B., Leg. 17, n. ${ }^{\circ} 8$, fols. 95v-97. Id., Leg. 18, n. ${ }^{\circ} 1$, s.f. 
dinero, a repartir en forma equitativa entre los tres clérigos que debian nombrarse.

Esta situación de nombramiento de clérigos por el señor se mantiene hasta 1570 sin ninguna intromisión por parte del prior de San Marcos ni del obispo de Córdoba, salvo una visita realizada en 1559 por el vicario de Estepa (perteneciente en este momento a la orden de Santiago), en nombre del prior de San Marcos, visita a la que se opone el bachiller Francisco Ruiz, que por nombramiento del señor servía a la sazón la iglesia de Benamejí. Sin embargo, esta visita parece que no llegó a tener mayores consecuencias ${ }^{11}$.

El detonante del conflicto surge en 1570, cuando D. Gonzalo de la Fuente, prior de San Marcos, puso como vicario de Benamejí a Gómez de los Reyes, cargo que ejercitó nominalmente desde 1570 hasta 1574, según los libros de bautismos, matrimonios y defunciones. El mismo D. Gonzalo de la Fuente realizó una visita a la iglesia de Benamejí, con motivo de la cual se llevó el primer libro de bautismos que incluía desde 1549 a 1570, hecho que se registra en el libro segundo (primero de los conservados), iniciado con este motivo ${ }^{12}$.

Desde este momento el pueblo apoya al señor en sus derechos y rechazan al enviado del prior de San Marcos:

«... los vezinos de la villa, como los que se creian exemptos de aquella sujecion, no solo no le reconocian por Prelado, pero (sic) sacavan a los hijos a bautizar fuera de la misma jurisdicion; y por libros antiguos bautismales de aquel tiempo parece les llevavan a las Cuevas Baxas, que es una aldea (donde ay Parrochia) en tierra, y dominio de la Ciudad de Antequera" ${ }^{13}$.

Este hecho está plasmado en el libro primero de bautismos, conservado en el Archivo Parroquial de Benamejí. En las primeras páginas se anotaban una serie de bautismos realizados en Cuevas con motivo de la protesta de los vecinos de Benameji por la intromisión del prior de San

"A.S.B., Leg. 17 , n. ${ }^{\circ} 8$, fols. $122 v-125$.

12 Archivo Parroquial de Benameji (APB), Sec. Bautismos, Leg. 1, n. ${ }^{\circ} 1$.

${ }^{13}$ A.S.B., Leg. $18, n .^{\circ} 3$, fols. 3v-4. 
Marcos en la jurisdicción eclesiástica de la villa uperteneciente al señor" ${ }^{14}$.

En esta fecha, Diego de Bernuy inició pleito con el prior. En 1571 éste introdujo nuevo vicario en la persona de Valcázar. El señor de Benamejí fue condenado, pero llevados los autos ante el Consejo Real se mandó al prior que aceptase la apelación; no obstante la cual, en 1572 el nuevo prior, D. Pedro Fernández de Criales, visita la iglesia de Benamejí, sin que nadie (ni concejo, ni vecinos, ni clérigo, ni señor) acudieran a darle la jurisdicción, de la que él se apropio con censuras.

En este ocasión el señor acudió ante el Nuncio apostólico que nombró como juez de la causa a Andrés Pérez de Buenrostro, Arcediano de Pedroche, dignidad de la iglesia de Córdoba, ante la que apelaron las partes.

El 14 de mayo de 1572, el caso encuentra una nueva dimensión al reclamar el obispo de Córdoba, Fresneda, la jurisdicción eclesiástica de la villa. El obispo alega que ésta no sólo está incluida en su reino, sino que también se incluye en sus tesorerias. Para avalar estos puntos presenta como prueba el testimonio de una sentencia que el provisor de Córdoba dio en una causa matrimonial entre vecinos de Benameji, en febrero de 1568 y el convenio citado entre el obispo Fernando de Mesa y el maestre de Santiago, Pelay Pérez ${ }^{15}$.

Con motivo de esta alegación, el visitador del obispado de Córdoba realizó una visita a la iglesia de Benamejí en 1574, en la que ajustó cuentas con una cofradía y dio algunas ordenanzas sobre registro de las misas y defunciones y sobre otros asuntos ${ }^{16}$. Estas actuaciones parece que fueron aisladas dentro del proceso, puesto que en adelante el obispo de Córdoba se inhibe de este tema y en adelante apenas vuelve a inmiscuirse en la controversia.

El 14 de febrero de 1575 se notificó la resolución al pleito interpuesto; por medio de una provisión se manda al prior de San Marcos deponer su actitud, dar por nulo todo lo hecho en Benameji y absolver a

\footnotetext{
${ }^{4}$ A.P.B., Sec. Bautismos, Leg. 1, n. ${ }^{\circ} 1,2,3,3 v$ y passim.

15 A.S.B., Leg. 18, n. $^{\circ} 3$, fols. $4 \mathrm{v}$.

16 Ibidem, Leg. 16, n. ${ }^{\circ} 41$, s.f.
} 
las personas que había excomulgado. El tema del uso de la jurisdicción eclesiástica de Benameji se remitió en discordia ${ }^{17}$.

Tal sentencia no fue cumplida y el 8 de abril de 1576 el prior manda a Benamejí a Pedro Morejón y al licenciado Cuenca con objeto de realizar una visita, presentando para ello una provisión de S.M. firmada en Aranjuez, el 12 de enero de 1574. A esta visita se vuelve a oponer el señor, alegando la sentencia que el año anterior dictó a su favor el Concejo Real ${ }^{18}$.

En este mismo año había sido nombrado por los patronos cura beneficiado D. Juan Guerrero.

En 1578 fue a Benamejí el licenciado Balmaseda, enviado por el vicario de Estepa, D. Miguel de Saldaña; de nuevo se le vuelve a negar la jurisdicción y con tal motivo excomulgó al alcalde mayor, alcaldes ordinarios y regidores de Benamejí, junto con el licenciado Guerrero y Miguel Manjarrés. La excomunión les fue levantada más tarde, a instancias del Consejo Real, primero por 80 días y después por 50, con multa de $10.000 \mathrm{mrs}$. al licenciado Juan Guerrero al que se le mandaba que no dijera misa ni administrase los sacramentos sin licencia del vicario de Estepa; el priorato de San Marcos alegaba contra el levantamiento definitivo de la excomunión el que los curas usaban de su oficio sin ser examinados por la Audiencia prioral, por lo que iban en contra de la iglesia, porque al no estar sujetos a ningún prelado y no tener facultad para administrar los sacramentos ni absolver, no se adecuaban a lo mandado por el Concilio de Trento y no teniendo jurisdicción in actu la ejercían. Respuesta que se dio tras remitirse el asunto al Consejo Real, el 8 de abril de $1579^{19}$.

De nuevo el 19 de diciembre de 1590 hubo intromisión por parte de San Marcos al entrar en Benameji el licenciado Diego de Quevedo, el cual

“... en desacato de lo mandado en dichas Reales Provisiones, el referido Diego de Quevedo, con otros, havian ido con capas pardas, som-

17 Ibidem, Leg. 18, n. ${ }^{\circ}$ 5, fols. 7-7v. A.P.B., Sec. Bautismos, Leg. 1, n. ${ }^{\circ} 1$, fol. 20.

18 A.S.B., Leg. 16, n. ${ }^{\circ} 5$, fols. $1-2$.

${ }^{19}$ Idem, Leg. $18, \mathrm{n}^{\circ} 5$, fols. $7 \mathrm{v}-9 \mathrm{v}$. 
breros y espadas y havian entrado en la Iglesia de dicha villa, y apoderandose de ella, tomando las llaves de sus puertas, y de la sacristia, ornamentos y joyas de oro, y plata, que el dicho Bernui, y sus antecesores havian dado de su propia hazienda y patrimonio. $Y$ no contentos con lo referido, inquietaban y perturbaban al vicario, y clerigos de dicha Iglesia, que estaban nombrados por el dicho Bernui, so color de una Provision, ganada con siniestra relación, sin declarar el estado de dicho pleito, librada por el Consejo de las ordenes, en que davan nombramiento de cura de dicha Iglesia al dicho Quevedo, quien procedia insolentemente, diciendo muchas palabras descompuestas, y ocasionadas, para que sucediessen muertes, y alborotos; y amenazando que havia de quemar al pueblo, y destruir todos los que en él estaban, y quitando los presos, y delinquentes al dicho Alcalde Mayor, y Alguaciles, obligandoles con obras, y palabras descompuestas a que perdiesen la paciencia, y executassen algun desatino" ${ }^{20}$.

Enviada información al Consejo se mandó al licenciado Quevedo que saliese de Benameji y lo dejase todo tal como lo había encontrado; en caso de incumplimiento se daba comisión al corregidor de Antequera para que ejecutase lo dicho.

Requeridos el prior de San Marcos y el provisor de Llerena sobre el asunto, alega el primero no haber dado comisión al licenciado Quevedo para lo que hizo y dio facultad a D. Pedro Martínez Navarrete, cura de Benamejí, para que levantase las excomuniones. El provisor de Llerena, por su parte, admitió haber dado comisión sólo para conocer de algunos casos que sucedian en Benamejí, por estar ésta lejos de Llerena, cabeza de la diócesis ${ }^{21}$.

A finales del siglo $x v i$ las partes llegaron a un compromiso según el cual el patrono nombraria a los clérigos que más tarde serian presentados ante el prior para su aprobación. La primera referencia que tenemos de esta práctica es de 1599, en la persona de Pedro Martínez Navarrete (vicario en 1591) ${ }^{22}$.

En otros aspectos menos conflictivos ya se habia llegado a acuerdos similares en la década anterior, a tenor de datos recogidos en los libros de bautismos, entre ellos que el 13 de enero de 1587 el obispo Fray

${ }^{20}$ Ibidem, fols. 10-10v.

${ }^{21} \mathrm{Ibidem}$, fols. 10v-11v. A.P.B., Sec. Bautismos, leg. 1, n. ${ }^{\circ}$, fol. 61.

${ }^{22}$ A.S.B., leg. $18, n{ }^{\circ} 5$, fols. $12-12$ v. 
Buenaventura de Nactani, con licencia del prior de San Marcos, D. Apolinario de Huergón, confirmara a 212 personas en la Iglesia de Benameji $^{23}$.

El sistema de nombramiento de los clérigos por los patronos y aprobación por el prior resolvió el conflicto durante casi un siglo (1599-1694), nombrándose sucesivamente a los siguientes clérigos:

Pedro Martínez Navarrete (1599).

Alonso Armijo Altamirano (hasta febrero de 1607).

Bartolomé de Lara (hasta abril de 1612).

Francisco Garcia de Córdoba (hasta 1623).

Alonso Navarrete Corbua (hasta 1654).

Antonio Carlos de Bernuy (hasta 1669).

Juan Antonio de Morales (que murió antes de ejercer su oficio).

Alonso de Palomeque y Pozo (hasta 1673) ${ }^{24}$.

Continuan los nombramientos hasta julio de 1694, fecha en la que el prior de San Marcos unilateralmente nombra vicario a $D$. Clemente Crespo. De nuevo empiezan los pleitos interpuestos por doña María Enríquez de Cabrera, marquesa de Benamejí, como tutora y curadora de su hijo Juan Ignacio de Bernuy.

El pleito se siguió en la Nunciatura; por auto de 5 de julio de 1695 se manda que las partes se aviniesen en el nombramiento de una persona que cubriera la vicaría. No consta que se diese sentencia definitiva sobre el derecho de nombrar vicario, juez eclesiástico y ordinario de Benameji.

${ }^{23}$ A.P.B., Sec. Bautismos, leg. 1, n. ${ }^{\circ} 1$, fols. 227-230.

${ }^{24}$ A.S.B., leg. $18, n^{\circ} 3$, fols. $7-7 \mathrm{v}$. Váse apéndice. 
Ante el desacuerdo de las partes y mientras se resolvía el pleito, el 3 de noviembre del mismo año el nuncio nombró a D. Juan Antonio Saénz de Trueba.

Apeló el prior y conoció la causa uno de los jueces in curia mandados por el Papa, que por auto del 18 de junio de 1698 declaró

«... pertenecer privativamente al prior del Real Convento de San Marcos de León y a su Dignidad Prioral, el nombramiento de Vicario Juez Eclesiastico para exercer la jurisdicción Eclesiastica en Benameji, y su Territorio con la facultad que le quisiesse dar, como verdadero Prelado Diocesano, que es de dicha Villa, sus vecinos y moradores. $Y$ assimismo declaro pertenecerle el derecho de nombrar Vissitador, que en su nombre visite la Iglesia Parrochial de la dicha Villa, y las demás, que estan debaxo de su jurisdiccion, y territorio, y todo lo que pudiera exercer el mismo Prior, si visitara personalmente" ${ }^{25}$.

La marquesa apeló y de nuevo por auto de 1 de junio de 1699 se confirmó todo lo anterior. Tras nueva apelación se llevó la causa a la Rota que volvió a confirmar la sentencia a favor del Prior, en 3 de julio de 1703.

En este año, haciendo ejecución de las letras rotales y para no volver a entrar en conflicto con los marqueses, fue enviado a Benameji D. Gregorio Holguín de Cáderes, fraile de la orden de Santiago, con la comisión de nombrar como vicario a la persona que la marquesa propusiere, cesando a D. Juan Antonio Saénz de Trueba, vicario interino nombrado por el Nuncio. La marquesa presentó a D. Francisco Thoribio Sánchez Calvo que aquél confirmó, tras haber hecho juramento de fidelidad y a quien el prior despachó título de vicario el 8 de abril de 1704 .

El 19 de febrero de 1705 el prior dio título y nombramiento de vicario, juez eclesiástico de Benameji (títulos que aparecen juntos normalmente) a D. Clemente Crespo, al que D. Francisco Thoribio negó cumplimiento alegando que dicho nombramiento estaba en contradicción con el derecho de patronato de los marqueses.

${ }^{25}$ Ibidem, leg. 18, n. $^{\circ} 5$, fols. $15-15 v$. 
De nuevo el prior apela ante el Nuncio, que mandó comisión al vicario de Lucena para que procediese a la ejecución de las letras rotales ganadas por el prior y para que nombrase vicario de Benamejí a D. Clemente Crespo; sobre lo que recurrió D. Francisco Thoribio ante la Chancillería de Granada, de donde se mandó al vicario de Lucena que restituyera en su puesto al mismo, que a la sazón estaba excomulgado por D. Clemente Crespo. Aquel fue restituido el 25 de enero de 1706.

El 16 de abril de 1708 se volvió a dar sentencia en la que se expresaba que:

“... no se pretendía perturbar, ni despojar a la dicha marquesa de Benameji de la posession en que estaba, y havian estado sus Ascendientes; pues los Executoriales sobre cuya retencion se litiga, no son en perjuicio de su Patronato, ni presentacion de su Beneficio-Curato, si solo determinacion del derecho de nombrar Vicario, Juez Eclesiastico visitador con la Omnimoda jurisdiccion Eclesiastica, que pretende el Prior de San Marcos de Leon toca a su Dignidad Prioral, cuya regalia no se concedio, ni expresó en el Privilegio y venta referida ni su uso puede pertenecer a los descendientes de dicho Diego de Bernui, por no haverse comprehendido en ella» ${ }^{26}$.

El pleito continúa durante el siglo XVIII, de cuya época tenemos muy pocos datos hasta el último decenio, alegando el prior causas como las cláusulas de los testamentos de Felipe II, Felipe III, Felipe IV y Carlos II sobre los territorios desmembrados y vendidos de las Ordenes Militares y su restitución a la Corona. Poniendo, finalmente, en 1794 tanteo a la venta del término de Benameji por Carlos IV ${ }^{27}$.

No obstante, durante este siglo parece que San Marcos de León ejerció la jurisdicción eclesiástica según consta en unas evaluaciones de los curatos pertenecientes a la orden, realizadas por los contadores Zárate y Zorrilla el 29 de enero de 1749 y conservadas en el A.H.N., en donde figura, entre los demás curatos, el de Benamejí, con un valor de 138.431 mrs., procedentes de los derechos de pie de altar y obenciones $^{28}$.

\footnotetext{
${ }^{26}$ Ibidem, fols. $16-20$ y $23 \mathrm{v}-24 \mathrm{v}$.

${ }^{27}$ Ibidem, Leg. 18, n. ${ }^{\circ} 8$, s.f., Jbidem, n. ${ }^{\circ} 11$, s.f.

${ }_{28}$ A.H.N., Ordenes Militares, consejo de las Ordenes, Leg. 5.403, s.f.
} 
Sin embargo, por una alegación conservada en el A.S.B., sabemos que los vicarios de Benamejí no tenían la omnímoda jurisdicción delegada del prior porque está limitada a las causas matrimoniales con dispensa. El prior se reserva la provisión de beneficios curados y la ejecución de todas las diligencias ${ }^{29}$.

A pesar de las ejecutorias ganadas por los priores y del uso efectivo de la jurisdicción eclesiástica, en distintos momentos hubo discrepancias en el concejo e incluso entre los mismos clérigos sobre la aceptación de los clérigos nombrados por el prior; sobre la legalidad de sus visitadores; la anulación del lugar preeminente en el coro de los capellanes mayores y la presidencia al cura beneficiado, antes elegido por el marqués, etc.

Además de los hechos mencionados respecto a la actitud popular durante el siglo XVI (cuando los vecinos llegaron a bautizar a sus hijos a iglesia distinta a Benameji en los momentos en que el clérigo era nombrado por el prior), uno de los episodios más significativos del tema a nivel popular es el registrado en enero de 1794, cuando llegó a Benamejí un clérigo de la Orden de Santiago, que se instaló en las casas del vicario y desde alli despachó autos como la prisión de D. Juan Quintero, capellán mayor de la iglesia, de avanzada edad, que en ese momento recibía una pensión del señor, como patrono que era de la iglesia. También se supo entre los vecinos que había venido a dar posesión del asiento preeminente del coro al señor vicario, lo que iba en contra de las regalías de los marqueses. Estos hechos desataron gran albotoro, que llegó a su punto álgido cuando por la noche el alguacil eclesiástico mostró en distintos lugares públicos cinco pares de grillos, los cuales dijo que eran para cinco eclesiásticos, hablando de ellos "en descredito de su onor i estimacion i lebantando cantares sobre estos particulares".

Como consecuencia de esto, el 5 de enero fue llamado todo el clero, que se reunió en la sacristía, de la que salieron a buscar al vicario para darle lugar preminente, de lo cual protestó el administrador del señor, momento en el que empezó a acudir gente a la plaza, que, finalmente, fueron acallados por el mismo administrador ${ }^{30}$.

Del mismo modo en varias ocasiones el vicario de Benameji (nombrado por el prior), con motivo de haber ido a predicar a Encinas Reales,

29 A.S.B., Leg. 18, n. ${ }^{\circ} 8$, s.f.

30 $\mathrm{Ibidem}$, Leg. 18, n. $^{\circ} 9$, s.f. 
lugar cercano a Benameji, se hizo acompañar a su vuelta por unos cien hombre a caballo, que entraron en Benameji alborotando, lo que fue una indudable muestra de intimidación al pueblo:

«... en dos ocasiones ha sido trasladado por los naturales de Encinas Reales y en numero de serca de 100 hombres a cabalio el señor vicario de esta Villa, con motivo de haver hido a predicar a dicha Puebla armados con escopetas y trabucos tirando tiros y en una de estas ocasiones y tiempo de Cuaresma, acompaño un victor con luses ensendidas, dejaron al señor Vicario en sus casas en cuyas puertas dejaron una descarga serrada, salio uno por la bentana de las casas de D. Juan Carreira, que son enfrente, dijo Silencio y continuo diciendo una relación burlesca que aludia a haverlo echo vien el señor Vicario en su sermon, y concluido tomaron de nuevo el victor, lo pasearon por las calles de esta Villa con gran desorden de gritos y tiros escandalisando a el vecindario y que don Josef Maria Moscoso, que era el corregidor de esta Villa se enserro y haviendo buelto el victor a las puertas del señor Vicario dieron otra descarga serrada lo colocaronle sus puertas y le ensensieron los luses" ${ }^{31}$.

Estos hechos removieron el pleito, que aún no se habia resuelto en 1807 , fecha en la que se hicieron las últimas actuaciones que hemos localizado ${ }^{32}$.

\section{CAUSAS QUE DESENCADENARON ESTOS HECHOS $Y$ CONSECUENCIAS}

Ante los hechos ocurridos, a partir de 1570 se pueden hacer una serie de reflexiones, principalmente desde dos puntos de vista:

- Actitud de los vecinos de Benameji.

- Legislación vigente en materia de patronato.

31 Ibidem.

${ }^{32}$ Idem, Leg. $18, \mathrm{n}^{\circ} 3$, fols. $6 \mathrm{v}-7 \mathrm{v}$, Idem, $\mathrm{n} .{ }^{\circ} 5$, fols. $13 \mathrm{v}-14 \mathrm{v}$. Idem, $n .{ }^{\circ} 9$, s.f. Idem, leg. $17, \mathrm{n} .{ }^{\circ} 6$, fols. $29-82$. 


\section{a) Actitud popular de los vecinos de Benameji}

¿Cuáles son las causas de la actitud de los vecinos ante las intromisiones del prior de San Marcos? Valdeón, centrando sus estudios en el siglo XIV y XV dice que uel antagonismo fundamental (en la pugna señores-campesinos) era el que oponía a los señores y a los campesinos (...). La pugna entre los señores y los campesinos fue el auténtico nudo gordiano de la historia social de la Castilla bajomedieval" ${ }^{33}$. Recogiendo esta teoría, pero matizándola para el caso de Andalucía, Yun Casalilla habla de la total ausencia de una acción común y de un movimiento generalizado de carácter agrario (...). Muy al contrario, lo que encontramos son acciones aisladas, vinculadas a la protesta contra causas más concretas, que nunca sobrepasan el marco local; $y$, junto a ello, un aumento de la agresividad y los antagonismos entre las villas vecinas, que solo en algunos casos pueden adquirir un matiz de tipo antiseñorial»» ${ }^{34}$.

De acuerdo con esto, el autor agrupa los conflictos en dos grandes apartados:

- Hechos y tensiones de tipo horizontal, frecuentemente vinculados a disputas de términos.

- Tensiones de tipo vertical, iniciados por la población de una villa o lugar contra un elemento "foráneo", política o económicamente más fuerte: la ciudad, un señor feudal, recaudadores de impuestos... ${ }^{35}$.

En este tipo de movimientos de tipo vertical es donde debemos incluir los acontecimientos de Benamejí, si bien no podemos incluirlos en ninguno de los epigrafes que dentro de ellos propone Yun Casalilla.

Varios tipos de causas pueden incidir en la actitud popular favorable al señor: En primer lugar el hecho de que la documentación consultada, conservada en el A.S.B., recoja principalmente las piezas del pleito rela-

33 J. VALDEON BERUQUE: Los conflictos sociales en el reino de Castilla en los siglos XIV $y \times V$, Madrid 19793 $15-16$.

34 B. Yun Casalilla: Crisis de subsistencias y conflictividad social en Córdoba, Córdoba $1980,157$.

${ }^{35}$ Ibidem. 
tivas a la defensa de los patronos, por lo que podemos tachar a esta documentación de parcial, aunque no dudemos de la veracidad de la misma, puesto que sus datos suelen coincidir con otras fuentes consultadas, como, por ejemplo, los libros parroquiales. Sin embargo hubiera sido nuestro deseo estudiar el pleito completo, que no hemos podido localizar.

En segundo lugar, nos inclinamos a creer que, por un lado, en el primer momento la población se sentía "endeudada" con el señor por la serie de ventajas que le había dado para su asentamiento en la nueva villa, postura que se fue haciendo "tradicional» en el comportamiento de la población, debido en gran parte a la actitud de los señores, que, salvo en la etapa final del período señorial, siempre fue benéfica, reflejo de lo cual son las declaraciones recogidas en este y otros pleitos ${ }^{36}$.

Por otro lado, es obvio que influyó en la actitud popular las consignas dadas por el concejo, cuyos cargos principales eran nombrados por el señor, y las tendencias de los mismos clérigos, asimismo de nombramiento señorial, como hemos visto ${ }^{37}$.

Finalmente existe otra causa que pudo influir decisivamente en la actitud popular: indudablemente la villa de Benamejí y Palenciana al poblarse empezaron a producir una serie de rentas que las hacian apetecibles, a diferencia del despoblado desmembrado de la Orden de Santiago en 1548. En la carta puebla ya se estipula el cobro por el señor de los diezmos y primicias, que luego se ampliaría también al cobro del llamado "voto de Santiago", los cuales fueron cobrados efectivamente, no sólo de forma nominal y que reportaban al señor cuantiosos beneficios a cambio de los cuales prometió (y cumplió) edificar una iglesia y a pagar los gastos del culto y mantenimiento de clérigos.

Puesto que el señor seguía cobrando los diezmos por el derecho que tenía en virtud de la carta de venta y la carta puebla, si el nombra-

${ }^{36}$ «(...) lo que causo general movimiento a todos los vecinos haverse privado a su Excelencia de las regalias y privilegios que le compete y que tanto bien esta haciendo a este pueblo desde que entro a gozar sus mayorazgos, no solo en el culto de la lglesia, tanto repartiendo limosnas publicas y secretas y lo es una de las publicas haver dado orden a su administrador don Geronimo de Hariza no vendiese las habas que tenia en su granero y que las repartiese entre sus pobladores diariamente, tanto en los vecinos de esta villa como los de su Aldea de Palenciana...". A.S.B., leg. 18, n. ${ }^{\circ} 9$, s.f.

${ }^{37}$ Vid. R. MORAN MARTIN: "El señorio de Benameji, 178 y ss. 
miento de los clérigos lo hacía San Marcos ¿de dónde saldrían los beneficios que al ejercer la jurisdicción eclesiástica sobre Benameji percibiria el priorato? Con seguridad del aumento de los derechos de estola y pie de altar (únicos en manos de los clérigos) y del derecho de visita, que efectivamente se incrementaron y que los vecinos no estaban dispuestos a sufragar (recuérdese los más de $130.000 \mathrm{mrs}$. que por derechos de pie de altar y obenciones recibía el priorato de San Marcos en 1742 por la tenencia de la iglesia de Benamejí).

\section{b) Evolución del derecho de patronato en la legislación}

Por último, analizamos a grandes rasgos, por no ser especialistas en el tema, el aspecto legal del problema, tema sobre el que existen escasos estudios.

Torres López, en varios trabajos sobre el origen de las iglesias propias y su tratamiento por los autores españoles, rebate la teoría de Ulrico Stutz sobre el origen germánico de las mismas y hace un profundo estudio de la legislación desde época romana a la visigótica, en el cual demuestra la existencia de la apropiación de iglesias por particulares en dichos periodos con las consiguientes restricciones que los distintos concilios italianos y españoles pretendian poner a su desarrollo ${ }^{38}$.

El mismo Torres López en un estudio sobre la carta puebla de Benamejí, citando a Cornejo, da una interpretación económica y señorial del regimen de "iglesias propias" como base de las posteriores percepciones de diezmos, demostrando, a través de este caso, la supervivencia de tal institución en el siglo XVI. Se plantea aquí la lucha por la desaparición de las mismas y la atracción por los obispos de Córdoba y León de los derechos que conllevan, que concluyen con la reducción de la iglesia propia existente durante el siglo $x \mathrm{VI}$ en patronato $\mathrm{y}$ presentación de clérigos ${ }^{39}$.

${ }^{38} M$. Torres LÓPEZ: "La doctrina de las "iglesias propias" en los autores españoles", en A.H.D.E., Madrid, 2, 1925, 412-418. Idem: "El origen del sistema de iglesias propias", en A.H.D.E., Madrid, V, 1928, 83-217.

${ }^{39}$ Idem: "La doctrina de las iglesias propias...", 425 y 446. Idem: "El origen del señorio solariego de Benamejí y su carta puebla de 1549", en Boletín de la Universidad de Granada, Granada, $21,1932,551-552$ y 554 . 
Reducido el derecho del señor a patronato laical y presentación de clérigos, desde el acuerdo con San Marcos a finales del siglo XVI, el problema que se plantea es el de la pertenencia de la jurisdicción eclesiástica. Hubiera sido lógico que se planteara este problema entre el prior y el obispo de Córdoba, como llegó a plantearse en 1574, y no entre el prior y el señor, puesto que éste no podía ejercer en ningún caso la jurisdicción, tal como se señaló, además, en alguna de las sentencias dadas por el nuncio. En este punto, como señala Aguirre, no se puede enunciar una regla general para dirimir las controversias que en materia de jurisdicción eclesiástica pueden suscitarse entre los ordinarios y los prelados de las Ordenes Militares, porque ni es igual la categoria de todos los priores, ni tampoco los privilegios de todas las Ordenes Militares.

"Deberán sin embargo aplicarse a los casos que concurran los principios de derecho común según los cuales existe siempre la presunción legal a favor de la jurisdicción ordinaria; y no probándose lo contrario se tiene como mejor el derecho del obispo; de manera que los prelados de las órdenes militares que pretenden tener jurisdicción espiritual oponiéndose a ella los obispos no pueden ejercerla sino en los casos espresos en su privilegio o en cualquier otro título legítimo que haga plena prueba en juicio" ${ }^{40}$.

Partiendo de este principio veremos en primer lugar el derecho de patronato en general para luego referirnos al caso concreto que nos ocupa.

Como ha demostrado Torres López, el derecho de patronato fue disfrutado por laicos desde época muy temprana. A nivel legal se enunciaba en las Siete Partidas, que a su vez recogía los preceptos de los concilios III y IV de Letrán, donde se habían fijado los principios que en

40 J. AguirRe: Disciplina eclesiástica general y particular de España, II, Madrid, $1857^{2}$, 325. Entre las obligaciones del patrono están el cuidado de que no se arruine la iglesia, ni falten los medios necesarios para su sustentación y sus ministros, defenderla contra las opresiones de los poderosos, impedir que sus bienes sean enajenados o dedicados a otra cosa que la señalada en su fundación "pero de ninguna de estas obligaciones puede inferirse que el patrono ejerza jurisdicción sobre las iglesias o beneficiados, ni sobre los bienes, y muchos menos que pueda administrarlos por sí o pedir cuentas de su administración ni de la cura de almas, ni tampoco que pueda ocuparlos, ni mezclarse bajo ningún pretesto en la percepción de frutos ni en la inspección de las cosas pertenecientes al culto, escepto lo prescrito en la fundación», Ibidem, 153-154. 
lo sucesivo habrían de regir los derechos de los patronos y que, junto con las Decretales, forman la disciplina general de la iglesia sobre el patronato ${ }^{41}$.

En cuanto al título para la provisión de cargos públicos eclesiásticos, además de los obispos

«... todos aquellos que por fundación, costumbre, prescripción o privilegio han adquirido títulos reputados como justos y legitimos para ejercerla, pero que es necesario probar para escluir de la provisión al obispo que tiene siempre a su favor la presunción de derecho» ${ }^{42}$.

Los Reyes Católicos en las Cortes de Toledo de 1480 establecieron la revocación de las donaciones por juro de heredad en favor de particulares para el disfrute de la prerrogativa del nombramiento de dignidades eclesiásticas. Ante la dificultad de dictar una revocación inmediata y total permitieron que los que ya poseian dicha facultad la disfrutaran hasta su muerte. Pero ellos mismos cedieron a particulares el derecho de patronato sobre las iglesias de Vizcaya. La única restricción impuesta en las donaciones en su carácter temporal, vitalicias, aunque no se descarta la posibilidad de confirmación de las mismas a los herederos ${ }^{43}$.

En el siglo XVı aún continúa el derecho de patronato en manos de particulares, a pesar de los recortes legales que la iglesia del momento imponía a la apropiación de iglesias.

Reunido el Concilio de Trento se realizan una serie de reformas sobre la jurisdicción eclesiástica, pero en el punto de intromisión de obispos en diócesis distintas a la suya o en lugares exentos de ella, se sigue conservando la misma postura, manteniendo los privilegios y no admitiendo intromisiones ${ }^{44}$.

41 Ibidem, III, 128. No tocaremos el modo de adquisición del patronato y sus distinciones; vid. Ibidem, 129-145. Q. ALDEA VAQUERO: voz "Patronato real de España" en Diccionario de Historia eclesiástica de España, III, Madrid 1973, pp. 1944 y ss. Partidas, I, tit. XV, leyes 1-15.

${ }^{42}$ Cap. 6. ${ }^{\circ}$ tít. 7. lib. Ill de las Decretales. Cap. 18, tít. XXVI, lib. II, Ibidem. Pár. 2. cap. 3, tít. XXXIII, lib. V de idem. Apud J. AguIRRE: Disciplina eclesiástica..., III, 90.

${ }^{43}$ A. M. ${ }^{a}$ GuILARTE: El régimen señorial en el siglo XVI, Madrid 1962, 249-252.

44 Concilio de Trento, Ses. XIV, cap. II y III. 
En cuanto al derecho de patronato, el Concilio respeta los casos tradicionales para su concesión: fundación o construcción de una nueva iglesia, beneficio o capellanía o dotación de una existente, pero con bienes insuficientes para su mantenimiento. El Concilio impone a los patronos la obligación de la presentación de los clérigos al obispo y de no cumplirse este requisito, el nombramiento sería nulo. Asimismo, a partir de este momento se impone la necesidad de que los clérigos sean examinados por el obispo o sus delegados antes de iniciar sus funciones ${ }^{45}$.

En cuanto al derecho de visita, el Concilio dice textualmente:

(...) que deba visitarlas, como delegado de la Santa Sede Apostólica, el obispo cuya iglesia catedral esté más proxima, si consta esto y a no constar, el que fuere elegido la primera vez en el concilio provincial por el prelado de aquel lugar sin que obsten ningunos privilegios, ni costumbre, aunque sean inmemoriales" ${ }^{46}$.

Entre los principales requisitos generales para la provisión de cargos públicos eclesiásticos se señalan:

- Título para ello.

- Que el puesto esté efectivamente vacante (bajo pena de excomunión si se cubre un beneficio cubierto).

- Examen del obispo o sus delegados. «Estando exentos del concurso los beneficios curados de patronato laical, el obispo 'debe instruir' al presentado por el patrono lego, si es de los aprobados en el concurso; y si no lo fuere, le sujetará a examen ante los mismos sinodiales, no instruyéndolo si no lo encuentra idóneo para el régimen de las almas» ${ }^{47}$.

Muchos de estos preceptos serán modificados por el Concordato de 1851, en el que no entramos por exceder del período en el que nos hemos centrado.

${ }^{45}$ Ibidem, cap. XII, ses. XXV; cap. IX y XIII, ses. XXIV; cap. XVIII.

${ }^{46}$ Ibidem, ses. XXIV, cap. IX.

${ }^{47}$ Ley 3. ${ }^{a}$, tít. XX, lib. I de la Nov. Recop. Apud. J. Aguirre: Disciplina eclesiástica..., III, 93-110. 
c) El caso de Benameji

Centrándonos en el caso de Benameji, cinco son los puntos que debemos tomar como referencia:

1. Privilegios de la Orden de Santiago en materia de jurisdicción eclesiástica.

2. Acuerdo entre el maestre de Santiago y el obispo de Córdoba en el siglo XIII.

3. Derechos adquiridos por el señor en la carta de venta y en la carta puebla.

4. Acuerdo entre el señor y el prior de San Marcos a finales del siglo XVI.

5. Tendencia general de la legislación eclesiástica a la reducción de los derechos de patronato. "(...) la raiz de la jurisdicion eclesiastica proviene de la divina comission; el origen de su respectiva delegacion debe ser la concession Pontificia».

La causa de esta concession a las Órdenes Militares pertenecientes al rey como administrador perpetuo de las mismas, asienta la legalidad de la jurisdicción eclesiastica de las Ordenes Militares, en un informe Impreso, sin fechar, conservado en el A.H.N. ${ }^{48}$.

A través de este informe se hace un estracto de las bulas concedidas en esta materia a las Ordenes Militares, entre las que sacaremos las referidas a la Orden de Santiago que afecta a nuestro tema.

Alejandro III, en 1175, en la Bula "Prima Confirmationis Ordinis", manda que en lugar donde hubiera obispo no pudiera reducirse su derecho porque «profecto in Parrochialibus Ecclesiis, quas habetis, nulumus

${ }^{48}$ A.H.N., Ordenes Militares, Consejo de las Ordenes, Leg. 5.403, s.n., fol. 5. Corresponde a una representación legal de las Bulas concedidas a las tres Ordenes Militares de Santiago, Alcántara y Calatrava. 
Episcopos suo iure fraudari", más adelante, sin embargo, señala "si autem en locis desertis, aut in ipsis terris Sarracenorum de novo Ecclesias construxeritis, Ecclesiae illae plena gaudeant libertate, nec aliqua per Episcopos decimarum, aut alterius rei exactione graventur" ${ }^{49}$.

Por esta Bula de Alejandro III $^{50}$ se da posibilidad a la orden para eximir la jurisdicción de sus tierras de los obispos circundantes. A este privilegio hubiese podido acogerse el prior en el caso que nos ocupa si en tiempo de su posesión hubiese edificado iglesia y puesto clérigo, lo que no llegó a hacer en ningún momento.

Gregorio IX ya inició el proceso de recorte de las facultades de los maestres de modo que distinguió entre las iglesias construidas y las iglesias que se contruyeran "previniendo que en las iglesias que se construyessen en adelante, podrán tener derecho en algunas los obispos, advirtió con suma perspicacia, que huviessen de ser examinados los Clerigos, y recibir la Cura Animarum de los obispos, quando debiessen estar las Plebes sujetas a estos Prelados", si bien en las iglesias que son de pleno derecho y la orden gozan de plena libertad no se tienen que acoger a este precepto ${ }^{51}$.

Más tarde, Martín $V$ eximió plenamente a la orden de la jurisdicción ordinaria, prohibiendo que ningún prelado tuviese jurisdicción, potestad, dominio, corrección o visita en ninguno de los conventos, lugares, personas, miembros, cosas y bienes de la orden. Por su parte, el arzobispo de Toledo había conseguido bula para poder visitar las iglesias, beneficios, lugares y encomiendas de las Órdenes Militares, bula que logró revocar Carlos I, como administrador perpetuo de los maestrazgos de las Ordenes Militares por Bula de Paulo III de 1542.

Finalmente, Julio III, por bula de 1556, manda que en adelante cualquier sentencia dada a los priores y vicario de la orden, no pueda apelarse a la Silla Apostólica, sin que primero se haya apelado al Consejo de las Ordenes ${ }^{52}$.

49 Ibidem, 7-9.

so Esta bula fue ratificada y especificada por Lucio III en 1184, Urbano III, Inocencio III, Honorio III, Gregorio IX e Inocencio IV. Gregorio IX dio además privilegio para que la Orden pudiera comparecer ante Roma en casos de usurpación de derechos, como asi lo hizo el prior de San Marcos.

${ }_{51}$ A.H.N., Ordenes Militares, Consejo de las Ordenes, Leg. 5.403, s.n., ff. 18-22.

52 Ibidem, 25-26. 
Para el caso que estudiamos a esta serie de privilegios concedidos a la orden tenemos que oponer el precepto del concilio de Trento referente a la visita, donde faculta al obispo de la catedral más próxima, si consta, y si no al que fuere elegido por primera vez en concilio provincial por prelado de dicho lugar. ¿Incluía el aspecto de la jurisdicción eclesiástica el convenio firmado entre el maestre y el obispo de Córdoba en 1262 ? Nos inclinamos por creer que sí, puesto que los derechos que se otorgan al obispo en este documento eran muy amplios: nombramiento de visitadores, cobro de derechos e incluso facultad para enajenar estos territorios, si bien se compromete a no enejanarlos a favor de orden o religión sin contar previamente con la aprobación del maestre.

Asi pues, creemos que del mismo modo que carece San Marcos del derecho a ejercer la jurisdicción eclesiástica sobre Benameji, por la carta de venta sólo se concede al señor el patronato, junto con el derecho de presentación de clérigos, derechos que él, mediante la carta de población y durante un período de veinte años convierte en la antigua y no desaparecida institución de "iglesia propia", hasta que sus derechos son recortados a finales del siglo xVI por el acuerdo con San Marcos y sucesivamente por las distintas sentencias a favor de la orden, a falta de una reivindicación efectiva por parte del obispo de Córdoba a quien hubiese correspondido de derecho dicha jurisdicción. Por último, el recorte en los derechos del señor se dio merced a la tendencia general que hemos visto en la legislación eclesiástica sobre la supresión del disfrute de derechos en las iglesias por parte de laicos. 


\section{APÉNDICE DOCUMENTAL}

Madrid, 12 de febrero de 1670 .

Nombramiento y presentación de clérigo de Benameji por el patrono, D. José Diego de Bernuy.

Copia simple incluida en el memorial del pleito entre el prior de San Marcos de León y el marqués de Benameji.

A.S.B., Leg. 18, n. $^{\circ} 3$, fol. $7 v-8$.

«Don Joseph Diego de Benuy Barba y Mendoza Benavides Cerda y Bazan, Mariscal de Alcala del Valle, Señor de la villa de Benamexy, y de la fortaleza de Gomez Arias, Villas, lurisdiciones, Castillos de Thomillos, y de Zumel, y de la Puebla de Palenciana, Patrono unico in solidum de la Iglesia Mayor, Iglesias y Hermitas de mi Estado de Benamexy, su demarcacion y territorio, etcétera. Vsando de el derecho, y preheminencias que por esta razon me tocan, $y$ en conocimiento de las prendas de calidad, virtud, y buenas letras que concurren en la persona de el doctor Don Alonso Palomeque y Poço, Presbitero y vezino de la ciudad de Antequera, le elijo, proveo y nombro por cura, Vicario, y Juez Ordinario Eclesiastico de la villa de Benamexy, y sus anexos, oficios que vacaron por muerte del Doctor Don Juan Antonio de Morales, ultimo Vicario, y en la forma referida le presento a el muy llustre Señor Prior de San Marcos de Leon, o a quien oy tiene su jurisdicion, y vezes, y le suplico, que continuando la costumbre que por aora reside en su 
Señoria se sirva de aprobar este nombramiento, y habilite, y mande exercer vnos y otros oficios al dicho Doctor Don Alonso de Palomeque y Poço, con todas sus dependencias, Preheminencias, y particularidades con que hasta aqui le han tenido y Usado sus antecessores. $Y$ aora para que conste de esta presentacion, la sello, firmo y mando despachar en la forma ordinaria. Dada en Madrid a doze dias del mes de Febrero de mil y seiscientos y setenta años. Mariscal de Alcala, Señor de Benamexy. Por mandado de su Señoria, D. Alonso de los Cobos y Osuna".

(San Marcos de León), 6 de marzo de 1670.

Confirmación del nombramiento por el prior de San Marcos.

Copia simple incluida en el memorial del pleito entre el prior de San Marcos de León y el Marqués de Benameji.

$$
\begin{aligned}
& \text { A.S.B., Leg. } 18, n .{ }^{\circ} 3 \text {, fols. } \\
& \text { 8-8v. }
\end{aligned}
$$

"Nos el Licenciado don Garcia de San Pelayo, del Orden de Santiago de la Espada, Governador del Real Convento de San Marcos de dicha Orden, extramuros de la Ciudad de Leon, Nullius Diocesis con jurisdicion Ordinaria quasi Episcopal en nuestra Provincia de Leon, y Extremadura, etc. Por quanto por parte del doctor Don Alonso Palomeque y Poço, Prebitero de la Ciudad de Antequera, se presento ante Nos la peticion retroescrita, con el nombramiento en el susohecho por el Señor Mariscal de Alcalá, para Cura, y Vicario, y Juez Ordinario de dicha villa de Venamexy, segun se 
refiere en dicho nombramiento: su fecha en Madrid a doze dias del mes de Febrero de mil y seiscientos y setenta años, firmado de dicho señor Mariscal, sellado, y refrendado de don Alonso de los Cobos y Osuna, su Secretario: Devemos de confirmar, y confirmamos, segun en dicho nombramiento se contiene, y damos licencia, y facultad a dicho doctor Don Alonso Palomeque y Poço para los dichos exercicios, y ministerios, y cada uno de ellos, como por derecho se requiere, y es necessario; y le instituimos Canonicamente en dicha Vicaria, y Curato de Benamexy. Y por quanto no ha parecido personalmente, damos licencia y comission en forma a qualquiera de los lectores de Theologia, Escolastica, o Moral, y a qualquiera de los Ordinarios de Ciudad de Antequera, y de la Cordova, para que pueda exminar al dicho doctor Don Alonso de $\mathrm{Pa}$ lomeque, y hallandole habil, y suficiente para el ministerio de tal Cura le dé licencia para el vso, exercicio, y administracion de los Santos Sacramentos; que Nos por la presente desde aora para quando preceda dicho examen, y licencia, se la damos, y concedemos segun dicho nombramiento, y sin limitacion, como lo han vsado sus antecessores, y han sido confirmados por los señores nuestros antecessores. $Y$ para que hecho el examen le puedan recibir, y reciba a que haga en sus manos la posession de la $\mathrm{Fe}$, conforme a los decretos de el Santo Concilio Tridentino; y mandamos se le acuda con todos los diezmos, frutos, rentas, y derechos judiciales, y extrajudiciales que en cualquiera manera le fueren devidos por razon de tal Cura, y Vicario de dicha Villa, sin perjuicio vno, ni otro de los derechos de nuestra Dignidad. En testimonio de lo qual mandamos dar, y dimos las presentes, firmadas, selladas y refrendadas en nuestro Real convento a seis dias del mes de Março de mil seiscientos y setenta años. Don Garcia de San Pelayo. Por mandado de su Señoria. Francisco Saez de Reyero, Notario". 